Eamon P. McCoy FFARCSI,

Venkat R. Maddineni MD FFARCSI,

Peter Elliott MD FRCAnaes,

Rajinder K. Mirakhur MD PhD FRCAnaes,

Ian W. Carson MD FFARCSI,

Ronald A. Cooper MD FFARCSI

\title{
Haemodynamic effects of rocuronium during fentanyl anaesthesia: comparison with vecuronium
}

Les variables hémodynamiques ont été mesurées après l'ad-

Haemodynamic variables were measured following administration of rocuronium $0.6 \mathrm{mg} \cdot \mathrm{kg}^{-1}$ or vecuronium $0.08 \mathrm{mg} \cdot \mathrm{kg}^{-1}$ (approximately equivalent to $2 \times E D_{95}$ doses) in patients anaesthetized with fentanyl $50 \mu \mathrm{g} \cdot \mathrm{kg}^{-1}$ and scheduled to undergo elective coronary artery bypass grafting. There were increases in stroke volume index $(+15 \%)$ and cardiac index $(+11 \%)$, and a decrease in pulmonary capillary wedge pressure (-25\%) following administration of rocuronium $(P<0.05)$. The changes in heart rate $(+7 \%)$, mean arterial pressure $(-5 \%)$, systemic vascular resistance $(-12 \%)$ and other measured or derived indices were insignificant. In comparison the administration of vecuronium was associated with decreases in heart rate $(-7 \%)$, mean pulmonary artery pressure $(-17 \%)$, central venous pressure $(-15 \%)$ and the rate-pressure product (-9\%) $(P<0.05)$. The changes in mean arterial pressure $(-7 \%)$, cardiac index $(-6 \%)$ and systemic vascular resistance $(-8 \%)$ following vecuronium were insignificant. There were no differences in any of the variables between rocuronium and vecuronium. The absolute values of all variables were, however, within acceptable clinical limits. There was no evidence of histamine release in any patient. The present study shows that rocuronium $0.6 \mathrm{mg} \cdot \mathrm{kg}^{-1}$ is associated with changes of only small magnitude in haemodynamic variables.

\section{Key words}

BLOOD PRESSURE: drug effects;

HEART: cardiac output;

MONITORING: ECG, blood pressure, venous pressure; NEUROMUSCULAR RELAXANTS: rocuronium, vecuronium; SURGERY: cardiac.

From the Departments of Anaesthesia, The Queen's University and the Royal Victoria Hospital, Belfast, Northern Ireland.

Address correspondence to: Dr. R.K. Mirakhur, Department of Anaesthetics, The Queen's University of Belfast, Whitla Medical Building, 97 Lisburn Road, Belfast, BT9 7BL, Northern Ireland (UK).

Accepted for publication 16th April, 1993. ministration de rocuronium $0,6 \mathrm{mg} \cdot \mathrm{kg}^{-1}$ ou de vécuronium $0,8 \mathrm{mg} \cdot \mathrm{kg}^{-1}$ (doses approximativement égales à $2 \times E D_{95}$ ) chez des patients anesthésiés avec du fentanyl $50 \mu \mathrm{g} \cdot \mathrm{kg}^{-1}$ et programmés pour subir une chirurgie de pontage aorlocoronarien en routine. Il y a une augmentation du volume d'éjection indexé $(+15 \%)$ et dindex cardiaque $(+11 \%)$ et une diminution de la pression capillaire pulmonaire bloquée $(-25 \%)$ après l'administration de rocuronium $(P<0,05)$. Les modifications de fréquence cardiaque $(+7 \%)$, de pression artérielle moyenne $(-5 \%)$, de résistance vasculaire systémique $(-12 \%)$ et des autres paramètres mesurés ou dérivés sont insignifiantes. Par comparaison, l'administration de vécuronium est associée avec une diminution de la fréquence cardiaque $(-7 \%)$, de la pression d'artère pulmonaire moyenne (-17\%), de la pression veineuse centrale (-15\%) et.du produit fréquence cardiaque-pression artérielle $(-9 \%)(P<0,05)$. Les modifications en pression artérielle moyenne $(-7 \%)$, en index cardiaque $(-6 \%)$ et en résis. tance vasculaire systémique $(-8 \%)$ après le vécuronium sont insignificates. Il n'y a aucune différence de variables entre le rocuronium et le vécuronium. Les valeurs absolues de toutes les variables se situent dans les limites cliniques acceptables. Des manifestations de libération d'histamine ne se sont présentées chez aucun patient. Cette étude montre que le rocuronium $0,6 \mathrm{mg} \cdot \mathrm{kg}^{-1}$ n'est associé qu'à de faibles modifications des variables hémodynamiques.

Cardiovascular stability is considered desirable in an ideal muscle relaxant. The introduction of vecuronium bromide and atracurium dibesylate considerably improved the flexibility in the clinical administration of muscle relaxants. The intermediate duration of action of these compounds is more suitable to the duration of action of the majority of routine surgery than that of any other clinically used nondepolarizing muscle relaxants. While in general both these agents provide cardiovascular stability, there have been reports of bradycardia with vecuronium and of histamine liberation with atracurium. ${ }^{1-5}$ In addition both have a relatively slow onset of action. ${ }^{6}$ Pipe- 
TABLE I Patient characteristics (mean \pm SD)

\begin{tabular}{lcc}
\hline & Rocuronium & Vecuronium \\
\hline$n$ & 10 & 10 \\
Age $(\mathrm{yr})$ & $54 \pm 7.4$ & $58 \pm 7.2$ \\
Weight $(\mathrm{kg})$ & $79 \pm 10.3$ & $74 \pm 4.6$ \\
Height $(\mathrm{cm})$ & $171 \pm 9.6$ & $169 \pm 6.5$ \\
Body surface area $\left(\mathrm{m}^{2}\right)$ & $1.95 \pm 0.18$ & $1.88 \pm 0.06$ \\
\hline
\end{tabular}

curonium and doxacurium which have been recently introduced, provide very good cardiovascular stability but are quite slow and long-acting. ${ }^{6}$

Rocuronium is a new aminosteroidal competitive muscle relaxant which, in animal studies, has been shown to have a more rapid onset of action and minimal cardiovascular and vagal side effects in doses of up to 3-4 $X \mathrm{ED}_{95}{ }^{7.8}$ Studies in humans have also confirmed the onset of action to be rapid with a duration of action resembling that of vecuronium. ${ }^{9,10}$

The detailed haemodynamic effects of the drug have not yet been reported although routine observations during early neuromuscular studies have not shown important cardiovascular side effects. ${ }^{10-12}$ The present study was undertaken to compare the haemodynamic effects of rocuronium with those of vecuronium during fentanyl anaesthesia in patients undergoing elective coronary artery bypass grafting (CABG).

\section{Methods}

Twenty ASA grade III or IV patients between the ages of 18 and $65 \mathrm{yr}$, scheduled to undergo elective CABG surgery, were included in the study after obtaining their written informed consent and approval from the Regional Ethics Committee. Patients with a body weight below $20 \%$ or above $35 \%$ of their ideal, those with a left ventricular ejection fraction of less than $50 \%$ or suffering from valvular heart disease or hepatic, renal or neuromuscular disorders were excluded from the study. All the patients were receiving the standard triple therapy of betaadrenergic receptor blocking drugs, calcium entry blocking drugs and nitrates. All preoperative medication was continued until the morning of surgery. All patients were in sinus rhythm on arrival in the operating room. The patients were premedicated with lorazepam 3-4 $\mathrm{mg}$ po and morphine $15-20 \mathrm{mg}$ and hyoscine $0.2 \mathrm{mg}$ im 60 to $90 \mathrm{~min}$ before surgery.

Monitoring of the heart rate and rhythm was commenced on arrival in the operating room. Peripheral arterial (radial) and venous cannulations and insertion of a multi-lumen pulmonary artery flotation catheter through the right internal jugular vein were carried out under local anaesthesia. Anaesthesia was induced with an infusion of fentanyl at a rate of $10 \mu \mathrm{g} \cdot \mathrm{kg}^{-1} \cdot \mathrm{min}^{-1}$ up to a total dose of $50 \mu \mathrm{g} \cdot \mathrm{kg}^{-1}$. Succinylcholine, 1 $\mathrm{mg} \cdot \mathrm{kg}^{-1}$, was administered at the loss of eyelash reflex to facilitate tracheal intubation. Ventilation was carried out with a mixture of air and oxygen, adjusted to maintain an end-tidal carbon dioxide concentration between 4.5 and $5.0 \%$. Stable anaesthesia was maintained by giving bolus doses of fentanyl, $1-5 \mu \mathrm{g} \cdot \mathrm{kg}^{-1}$, as required. A Datex Relaxograph (Datex Instrumentation Corporation, Helsinki, Finland) was used to demonstrate recovery from the effects of succinylcholine.

Following recovery from succinylcholine and haemodynamic stabilization (approx $15 \mathrm{~min}$ ) baseline recordings of heart rate (HR, computed by the monitor from an average of 4-8 R-R intervals), mean systemic arterial pressure (MAP), mean pulmonary artery pressure (MPAP), central venous pressure (CVP), pulmonary capillary wedge pressure (PCWP) and cardiac output (CO) were made. The zero point was taken as the mid-axillary line. Cardiac output determinations were made in triplicate at the end of expiration by thermodilution technique using $10 \mathrm{ml}$ iced $5 \%$ dextrose in water, each time using a cardiac output computer (Edwards Laboratories $9520 \mathrm{~A}$ ). The mean of the three readings was taken as the $\mathrm{CO}$ for each time. All the monitoring (haemodynamic, end-tidal $\mathrm{CO}_{2}$ and pulse oximetry) was carried out using Hewlett-Packard Merlin model 68S.

Cardiac Index (CI), stroke volume index (SVI), left ventricular stroke work index (LVSWI), right ventricular stroke work index (RVSWI), systemic vascular resistance (SVR), pulmonary vascular resistance (PVR) and rate pressure product (RPP) were derived from the measured haemodynamic variables using standard formulae.

Following baseline recording, the patients were randomly allocated to receive rocuronium $0.6 \mathrm{mg} \cdot \mathrm{kg}^{-1}$ or vecuronium $0.08 \mathrm{mg} \cdot \mathrm{kg}^{-1}$, these being the approximately $2 \times \mathrm{ED}_{95}$ doses of the two relaxants. ${ }^{13,14}$ All the haemodynamic measurements were repeated $1,3,5$ and $10 \mathrm{~min}$ after the injection of the relaxants.

All patients received about $5 \mathrm{ml} \cdot \mathrm{kg}^{-1} \cdot \mathrm{hr}^{-1}$ of lactated Ringer's solution during the study period. There was no surgical stimulation during the study period.

Statistical analysis of the results for each variable within each group was carried out by repeated measures analysis of variance. Comparisons for each variable between the two groups were made using one-way analysis of variance and $t$ tests with Bonferroni correction if indicated.

\section{Results}

The groups were comparable with respect to average age, height, weight and body surface area (Table I). Average values of haemodynamic variables before and after relaxant administration are shown in Table II. The per- 
TABLE II Main haemodynamic variables before anaesthesia (awake), prior to the relaxant administration ( 0 ) and one, three, five, and ten minutes later (mean \pm SD)

\begin{tabular}{|c|c|c|c|c|c|c|}
\hline & Awake & 0 & 1 & 3 & 5 & 10 \\
\hline \multicolumn{7}{|l|}{ HR } \\
\hline - Roc & $65 \pm 17.2$ & $61 \pm 13.1$ & $60 \pm 13.9$ & $62 \pm 14.9$ & $65 \pm 14.1$ & $64 \pm 14.5$ \\
\hline - Vec & $63 \pm 11.6$ & $59 \pm 10.8^{*}$ & $59 \pm 11.6$ & $56 \pm 8.6$ & $55 \pm 9.0$ & $55 \pm 8.0$ \\
\hline \multicolumn{7}{|l|}{ MAP } \\
\hline - Roc & $97 \pm 16.0$ & $86 \pm 18.9$ & $84 \pm 20.6$ & $82 \pm 19.9$ & $83 \pm 17.7$ & $83 \pm 18.0$ \\
\hline$-V_{e c}$ & $92 \pm 20.2$ & $85 \pm 22.1$ & $82 \pm 17.9$ & $79 \pm 16.7$ & $79 \pm 16.4$ & $81 \pm 20.5$ \\
\hline \multicolumn{7}{|l|}{ MPAP } \\
\hline - Roc & $18.6 \pm 6.5$ & $18.3 \pm 3.7$ & $17.8 \pm 4.1$ & $16.5 \pm 5.3$ & $15.0 \pm 3.6$ & $16.3 \pm 4.3$ \\
\hline - Vec & $14.3 \pm 5.5$ & $16.9 \pm 5.4^{*}$ & $16.5 \pm 4.8$ & $15.2 \pm 3.5$ & $14.0 \pm 3.4$ & $14.4 \pm 3.7$ \\
\hline \multicolumn{7}{|l|}{ PCWP } \\
\hline - Roc & $10.6 \pm 3.8$ & $11.1 \pm 3.4^{*}$ & $10.1 \pm 2.6$ & $9.5 \pm 2.1$ & $8.8 \pm 2.5$ & $8.3 \pm 3.0$ \\
\hline - Vec & $10.4 \pm 4.0$ & $10.9 \pm 4.8$ & $9.2 \pm 2.5$ & $9.7 \pm 2.7$ & $9.4 \pm 2.5$ & $9.4 \pm 2.5$ \\
\hline \multicolumn{7}{|l|}{ CVP } \\
\hline - Roc & $8.6 \pm 2.8$ & $8.7 \pm 2.2$ & $8.5 \pm 2.6$ & $8.5 \pm 3.6$ & $7.1 \pm 2.7$ & $7.9 \pm 3.3$ \\
\hline - Vec & $6.8 \pm 3.4$ & $8.7 \pm 3.9^{*}$ & $8.3 \pm 3.8$ & $7.6 \pm 3.7$ & $7.4 \pm 3.5$ & $7.5 \pm 3.7$ \\
\hline \multicolumn{7}{|l|}{$\mathrm{CI}$} \\
\hline - Roc & $2.80 \pm 0.33$ & $2.47 \pm 0.52^{*}$ & $2.74 \pm 0.59$ & $2.71 \pm 0.58$ & $2.67 \pm 0.47$ & $2.63 \pm 0.47$ \\
\hline - Vec & $2.66 \pm 0.45$ & $2.53 \pm 0.42$ & $2.53 \pm 0.48$ & $2.50 \pm 0.53$ & $2.47 \pm 0.55$ & $2.38 \pm 0.47$ \\
\hline \multicolumn{7}{|l|}{ SVI } \\
\hline - Roc & $45.4 \pm 10.3$ & $41.0 \pm 9.6^{*}$ & $47.2 \pm 11.8$ & $44.6 \pm 8.7$ & $42.6 \pm 7.3$ & $42.4 \pm 7.3$ \\
\hline - Vec & $42.2 \pm 6.5$ & $43.3 \pm 9.9$ & $43.4 \pm 7.6$ & $44.4 \pm 8.7$ & $44.9 \pm 8.0$ & $44.1 \pm 8.5$ \\
\hline \multicolumn{7}{|l|}{ SVR } \\
\hline - Roc & $1329 \pm 346$ & $1307 \pm 319$ & $1144 \pm 256$ & $1148 \pm 305$ & $1180 \pm 281$ & $1183 \pm 282$ \\
\hline - Vec & $1321 \pm 455$ & $1363 \pm 513$ & $1281 \pm 279$ & $1260 \pm 262$ & $1280 \pm 327$ & $1453 \pm 479$ \\
\hline \multicolumn{7}{|l|}{ PVR } \\
\hline - Roc & $148 \pm 91$ & $122 \pm 52$ & $112 \pm 61$ & $124 \pm 101$ & $98 \pm 51$ & $128 \pm 45$ \\
\hline - Vec & $81 \pm 41$ & $105 \pm 60$ & $126 \pm 38$ & $99 \pm 21$ & $88 \pm 45$ & $92 \pm 39$ \\
\hline \multicolumn{7}{|l|}{ LVSWI } \\
\hline - Roc & $59.3 \pm 14.6$ & $47.6 \pm 15.9$ & $54.1 \pm 18.9$ & $49.9 \pm 14.6$ & $48.1 \pm 12.4$ & $47.9 \pm 14.6$ \\
\hline - Vec & $53.4 \pm 14.4$ & $49.3 \pm 13.2$ & $48.5 \pm 15.5$ & $48.1 \pm 14.4$ & $47.8 \pm 11.5$ & $52.1 \pm 17.4$ \\
\hline \multicolumn{7}{|l|}{ RVSWI } \\
\hline - Roc & $12.9 \pm 6.3$ & $10.2 \pm 3.2$ & $11.3 \pm 4.8$ & $10.1 \pm 4.3$ & $8.9 \pm 3.4$ & $9.7 \pm 4.0$ \\
\hline$-\mathrm{Vec}$ & $8.3 \pm 3.7$ & $10.1 \pm 4.4$ & $9.9 \pm 4.4$ & $9.2 \pm 3.1$ & $8.4 \pm 1.9$ & $8.6 \pm 2.5$ \\
\hline \multicolumn{7}{|l|}{ RPP } \\
\hline - Roc & $9529 \pm 3619$ & $8010 \pm 2976$ & $7327 \pm 3017$ & $7676 \pm 3361$ & $7941 \pm 3051$ & $7654 \pm 2682$ \\
\hline - Vec & $8262 \pm 1779$ & $7003 \pm 2317^{*}$ & $7014 \pm 2135$ & $6662 \pm 2042$ & $6499 \pm 2059$ & $6406 \pm 1927$ \\
\hline
\end{tabular}

Roc $=$ rocuronium; $\mathrm{Vec}=$ vecuronium; $\mathrm{HR}=$ heart rate $\left(\right.$ beats $\left.\cdot \mathrm{min}^{-1}\right) ; \mathrm{MAP}=$ mean arterial pressure $(\mathrm{mmHg}) ; \mathrm{MPAP}=$ mean pulmonary artery pressure $(\mathrm{mmHg}) ; \mathrm{PCWP}=$ pulmonary capillary wedge pressure $(\mathrm{mmHg}) ; \mathrm{CVP}=$ central venous pressure $(\mathrm{mmHg}) ; \mathrm{CI}=$ cardiac index $\left(\mathrm{L} \cdot \mathrm{min}^{-1} \cdot \mathrm{m}^{-2}\right) ; \mathrm{SVI}=$ stroke volume index $\left(\mathrm{ml} \cdot\right.$ beat $\left.{ }^{-1} \cdot \mathrm{m}^{-2}\right) ; \mathrm{SVR}=$ systemic vascular resistance $\left(\mathrm{dyn} \cdot \mathrm{s} \cdot \mathrm{cm}^{-5}\right) ; \mathrm{PVR}=$ pulmonary vascular resistance $\left(\right.$ dyn $\left.\cdot \mathrm{s}^{\cdot} \mathrm{cm}^{-5}\right)$; LVSWI and RVSWI = Left and right ventricular stroke work index $\left(\mathrm{g} \cdot \mathrm{m} \cdot\right.$ beat $\left.{ }^{-1} \cdot \mathrm{m}^{-2}\right) ; \mathrm{RPP}=$ rate pressure product $\left(\mathrm{mmHg} \cdot\right.$ beats $\left.\cdot \mathrm{min}^{-1}\right)$. Awake measurements were made about $15 \mathrm{~min}$ after insertion of arterial, venous and pulmonary artery cannulae. *Difference significant $(P<0.05)$ from subsequent measurements.

centage changes in heart rate, mean arterial pressure, stroke volume index and cardiac index are shown in the Figure. There were no significant changes in HR and MAP in patients who received rocuronium. There were small increases in $\mathrm{CI}(+11 \%)$ and SVI $(+15 \%)(P<$ 0.05 ) in patients who received rocuronium, with peak changes at one minute following the administration of the relaxant and there was a reduction in PCWP $(-25 \%)$ $(P<0.05)$. The rest of the measured variables or indices did not show any significant changes.

The group of patients who received vecuronium had a small reduction in heart rate $(-7 \%)(P<0.05)$, most prominent at five and ten minutes following administration of the drug. There was a small but significant reduction in MPAP $(-17 \%)$, CVP $(-15 \%)$ and RPP $(-9 \%)$. The changes in MAP and CI did not attain statistical significance. Likewise changes in other measured haemodynamic variables or indices in this group did not attain statistical significance.

There were no differences between rocuronium and vecuronium in any of the variables at any time. There was no evidence of histamine release following the administration of either relaxant in any patient. No changes suggestive of ischaemia were observed in any patient. 

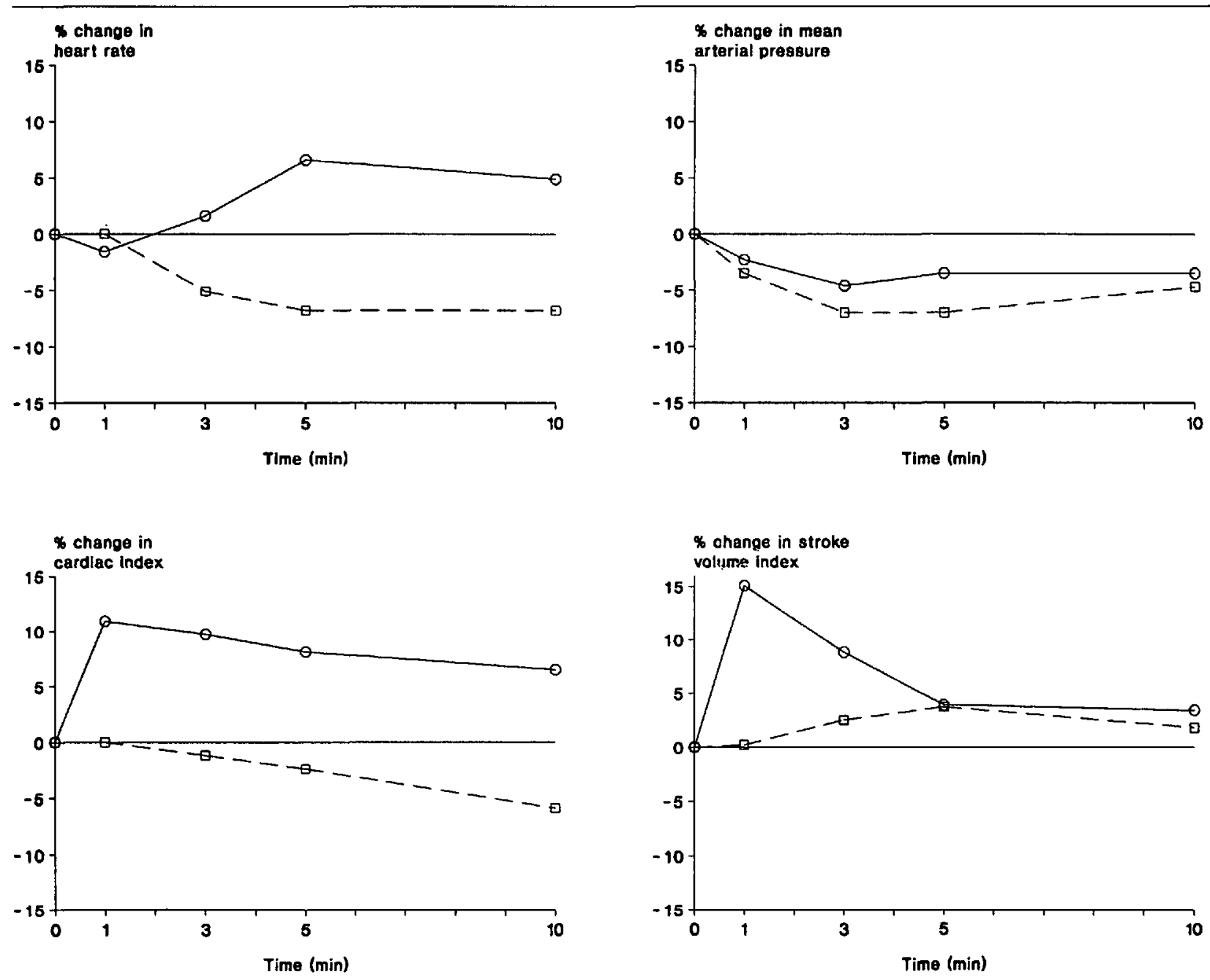

FIGURE Per cent changes in heart rate, mean arterial pressure, stroke volume index and cardiac index following rocuronium $0.6 \mathrm{mg} \cdot \mathrm{kg}^{-1}$, and vecuronium $0.08 \mathrm{mg} \cdot \mathrm{kg}^{-1}$ (rocuronium $\mathrm{O} \longrightarrow \mathrm{O}$, vecuronium $\mathrm{Q}-\ldots \ldots$. . .

\section{Discussion}

Haemodynamic stability is an integral and essential goal of any anaesthetic management plan in patients with cardiac disease. ${ }^{15}$ Patients who have limited coronary reserve are susceptible to any factors which increase myocardial oxygen demand, such as increases in heart rate, blood pressure, myocardial contractility, or the systemic and pulmonary vascular resistance. This may either induce or worsen pre-existing ischaemia which may be associated with an increased incidence of postoperative myocardial infarction. ${ }^{16,17}$ It would therefore be reasonable to avoid any agents, including muscle relaxants, which give rise to stimulation of the cardiovascular system and thus increase myocardial oxygen demand. ${ }^{18}$ The present study showed that both rocuronium and vecuronium were associated with clinically unimportant haemodynamic changes, although the changes in some variables were occasionally statistically significant.
Vecuronium has previously been reported to maintain excellent cardiovascular stability. ${ }^{19-21}$ This was in general confirmed for the dose used in the present study. There are reports of bradycardia following its use $e^{4,5,22}$ but these are generally felt to be related to the use of high doses of fentanyl, absence of surgical stimulation or during periods of vagal stimulation. ${ }^{19,23}$ There was a decrease in heart rate following vecuronium administration in the present study but the average maximum decrease was only of the order of five beats per minute, a decrease hardly of any clinical significance.

Rocuronium doses of up to $3 \times \mathrm{ED}_{90}$ in dogs was not associated with any changes in the cardiovascular system although doses of $5 \times \mathrm{ED}_{90}$ have been reported to give rise to some tachycardia. ${ }^{8}$ Muir et al. have shown, in anaesthetized cats, that the neuromuscular blocking doses of rocuronium produced only a small effect on the chronotropic responses to vagal stimulation and no 
effect on the responses of the nictitating membrane to preganglionic stimulation. ${ }^{7}$ Equieffective neuromuscular blocking doses of vecuronium produced no effect on either vagal or nictitating membrane responses. Rocuronium is three to six times less potent than vecuronium as a neuromuscular blocker but is slightly more potent in blocking the responses to either vagal or preganglionic sympathetic stimulation. ${ }^{7}$ Therefore the margin between the neuromuscular blocking effect and the unwanted vagal blocking action is less than that of vecuronium; the vagal:neuromuscular block ratio for rocuronium was one-seventh (pig) to one-tenth (cat) that of vecuronium. Thus the slight increase in heart rate (a possible vagal blocking effect) along with an increased stroke volume index (indicating an increased contractility) produce the slight increase in cardiac index observed in the present study. It could thus be argued that rocuronium has mild ionotropic effects.

The lack of a chronotropic effect with vecuronium may allow the heart rate to decrease to unacceptably low levels in certain circumstances such as patients receiving betablocking drugs or high-dose fentanyl anaesthesia. Bradycardia and hypotension caused by many of the commonly used anaesthetic techniques may make drugs with a mild vagal blocking effect more acceptable than drugs with complete lack of cardiovascular effects. In this respect rocuronium with mild vagolytic effect would have an advantage over vecuronium, especially during highdose fentanyl anaesthesia.

The maximum average increase of about $7 \%$ in heart rate is far smaller and clinically acceptable than the increase of $32 \%$ reported recently by Booth et al. ${ }^{24}$ The increase may be due to relatively light anaesthesia in that study in comparison to a relatively high dose of fentanyl used in the present study. The duration of this tachycardia was not stated by Booth et al. This increase is even more than that reported after the use of pancuronium, a drug with more pronounced vagolytic effect. ${ }^{18}$ Such an increase by Booth et al. is at variance with other reports of only minimal changes in cardiovascular parameters with similar or even higher doses of rocuronium. ${ }^{11,12,25}$ Although there were small but significant increases in cardiac index and stroke volume index following rocuronium, the changes were well within the acceptable clinical limits. Newer relaxants such as doxacurium and pipecuronium also have the virtue of good cardiovascular stability. ${ }^{18,26}$ However, these are slow in onset and long in duration of action. Rocuronium has the advantage of a rapid onset and an intermediate duration of action.

The results of the present study indicate that rocuronium, in clinical doses, is associated with good haemodynamic stability in ASA grades III or IV patients undergoing elective coronary artery bypass grafting. Its histamine-releasing potential is minimal. ${ }^{27}$ This along with a mild sympathomimetic property may offer an advantage during high-dose fentanyl anaesthesia.

\section{Acknowledgements}

Supplies of rocuronium and financial assistance were received from Organon Teknika NV, Belgium. We are grateful to our colleagues in the cardiac, anaesthetic and surgical teams for their help and patience during the study.

\section{References}

1 Mirakhur RK, Lyons SM, Carson IW, Clarke RSJ, Ferres CJ, Dundee JW. Cutaneous reaction after atracurium (Letter). Anaesthesia 1983; 38: 818-9.

2 Mirakhur RK, Lavery GG, Clarke RSJ, Gibson FM, McAteer $E$. Atracurium in clinical anaesthesia: effect of dosage on onset, duration and conditions for tracheal intubation. Anaesthesia 1985; 40: 801-5.

3 Lavery GG, Boyle MM, Mirakhur RK. Probable histamine liberation with atracurium. Br J Anaesth 1985; 57: 811-3.

4 Kirkwood I, Duckworth RA. An unusual case of sinus arrest (Letter). Br J Anaesth 1983; 55: 1273.

5 Milligan KR, Beers $H T$. Vecuronium-associated cardiac arrest (Letter). Anaesthesia 1985; 40: 385.

6 Mirakhur RK. Newer neuromuscular blocking drugs. An overview of their clinical pharmacology and therapeutic use. Drugs 1992; 44: 182-99.

7 Muir AW, Houston J, Green $K L$, Marshall RJ, Bowman WC, Marshall IG. Effects of a new neuromuscular blocking agent (ORG 9426) in anaesthetized cats and pigs and in isolated nerve-muscle preparations. $\mathrm{Br} J$ Anaesth 1989; 63: 400-10.

8 Cason B, Baker DG, Hickey RF, Miller RD, Agoston S. Cardiovascular and neuromuscular effects of three steroidal neuromuscular blocking drugs in dogs (ORG 9616, ORG 9426, ORG 9991). Anesth Analg 1990; 70: 382-8.

9 Foldes FF, Nagashima $H$, Nguyen HD, Schiller WS, Mason MM, Ohta $Y$. The neuromuscular effects of ORG 9426 in patients receiving balanced anesthesia. Anesthesiology 1991; 75: 191-6.

10 Cooper R, Mirakhur RK, Clarke RSJ, Boules Z. Comparison of intubating conditions after administration of ORG 9426 (rocuronium) and suxamethonium. Br J Anaesth 1992; 69: 269-73.

11 Wierda JMKH, De Wit APM, Kuizenga K, Agoston S. Clinical observations on the neuromuscular blocking action of ORG 9426, a new steroidal nondepolarizing agent. $\mathrm{Br} \mathrm{J}$ Anaesth 1990; 64: 521-3.

12 Booij LHDJ, Knape HTA. The neuromuscular blocking effect of ORG 9426. A new intermediately-acting steroidal non-depolarizing muscle relaxant in man. Anaesthesia 1991; 46: 341-3. 
13 Gibson FM, Mirakhur RK, Clarke RSJ, Lavery GG. Comparison of cumulative and single bolus dose techniques for determining the potency of vecuronium. B J Anaesth 1985; 57: 1060-2.

14 Cooper RA, Mirakhur RK, Eliott P, McCarthy GJ. Estimation of the potency of ORG 9426 using two different modes of nerve stimulation. Can J Anaesth 1992; 39 : 139-42.

15 Gallo JA, Cork RC, Puchi P. Comparison of effects of atracurium and vecuronium in cardiac surgical patients. Anesth Analg 1988; 67: 161-5.

16 Kaplan JA, Dunbar RW, Jones EL. Nitroglycerin infusion during coronary-artery surgery. Anesthesiology 1976; 45 : 14-21.

17 Slogoff $S$, Keats $A S$. Does perioperative myocardial ischaemia lead to postoperative myocardial infarction? Anesthesiology 1985; 62: 107-14.

18 Stanley JC, Carson IW, Gibson FM, et al. Comparison of the haemodynamic effects of pipecuronium and pancuronium during fentanyl anaesthesia. Acta Anaesthesiol Scand 1991; 35: 262-6.

19 Morris RB, Cahalan MK, Miller RD, Wilkinson PL, Quasha $A L$, Robinson $S L$. The cardiovascular effects of vecuronium (ORG NC45) and pancuronium in patients undergoing coronary artery bypass grafting. Anesthesiology 1983; 58: 438-40.

20 Ferres CJ, Carson IW, Lyons SM, Orr IA, Patterson CC, Clarke RSJ. Haemodynamic effects of vecuronium, pancuronium and atracurium in patients with coronary artery disease. Br J Anaesth 1987; 59: 305-11.

21 Rorvik K, Husby P, Gramstad L, Vamnes JS, BitschLarsen $L$, Koller $M-E$. Comparison of large dose of vecuronium with pancuronium for prolonged neuromuscular blockade. Br J Anaesth 1988; 61: 180-5.

22 Mirakhur RK, Ferres CJ, Clarke RSJ, Bali IM, Dundee $J W$. Clinical evaluation of ORG NC45. Br J Anaesth 1983; 55: 119-24.

23 Lavery GG, Mirakhur RK, Clarke RSJ, Gibson FM. The effect of atracurium, vecuronium and pancuronium on heart rate and arterial pressure in normal individuals. Eur J Anaesthesiol 1986; 3: 459-68.

24 Booth MG, Marsh B, Bryden FMM, Robertson EN, Baird $W L M$. A comparison of the pharmacodynamics of rocuronium and vecuronium during halothane anaesthesia. Anaesthesia 1992; 47: 832-4.

25 Cooper RA, Mirakhur RK, Maddineni VR. Neuromuscular effects of rocuronium bromide (ORG 9426) during fentanyl and halothane anaesthesia. Anaethesia 1993; 48: 103-5.

26 Emmot RS, Bracy BJ, Goldhill DR, Yate PM, Flynn PJ. Cardiovascular effects of doxacurium, pancuronium and vecuronium in anaesthetized patients presenting for coronary artery bypass surgery. $\mathrm{Br} J$ Anaesth 1990; 65: 480-86.
27 Davis GK, Szlam F, Lowdon JD, Levy JH. Evaluation of histamine release following ORG 9426 administration using a new radio-immunoassay. Anesthesiology 1991; 75: A818. 